\title{
Digital Contemplative Community in Pandemic Times
}

\author{
LISETTE E. TORRES, Nebraska Wesleyan University
}

In this collage, I reflect on my Radical Dharma (williams \& Owens, 2016) community gatherings, which are led by Zen teacher Rev. angel Kydoo williams, and examine how they are helping me to (re)imagine community and connection during pandemic times. Using the theoretical frameworks of Critical Race Theory (CRT) (Delgado \& Stefancic, 2001) and Dis/ability Critical Race Studies (DisCrit) (Annamma, Connor, \& Ferri, 2013), I explore through my artwork the following questions: How is COVID-19 changing the way I, as a disabled Latina mother-scholar, relate to others in person and over digital space? Is physical distancing creating more social isolation and separation? Or is it paradoxically making me more attune to the pain, needs, and wants of my fellow beings on this planet? How does this ultimately impact my scholarship?

Through the use of meditation, journaling, and reflecting on our virtual meetings, I tried to express within the collage our coming to terms with change and grief within the context of the pandemic and the current Black Lives Matter (BLM) protests on police brutality. I argue that we are in the midst of creating a virtual fugitive space (Stovall, 2015), as depicted by the center circle of golden leaves, where we can (re)imagine what community can look like post-pandemic through embodied contemplative practice and collective care (Piepzna-Samarasinha, 2018). We are using computer-mediated technology (e.g., Zoom, Slack, Teamwork Projects) to not only work on community mending (Ortiz, 2018) for communities of color, but also their (and our) liberation. The focus on love, intuition, and spiritual beginnings/endings is represented by the pink center of the circle.

What brings me and my fellow meditators together is suffering and our need to collectively mend, even if it is mediated by computers. The red acrylic paint on the top right of the collage symbolizes the blood and death that we have experienced during this pandemic moment. The purple cracks found throughout the work are scars of wounds inflicted. The black handprint is symbolic of the battle for human life, particularly Black lives. Moving down the collage to the bottom right corner, the red transitions to blue acrylic to represent the sweat and tears that have been shed. The blue is also reminiscent of water and drowning, as indicated by the rope and light brown stick figure being saved by the dark brown bodhisattva in the middle of the collage. 


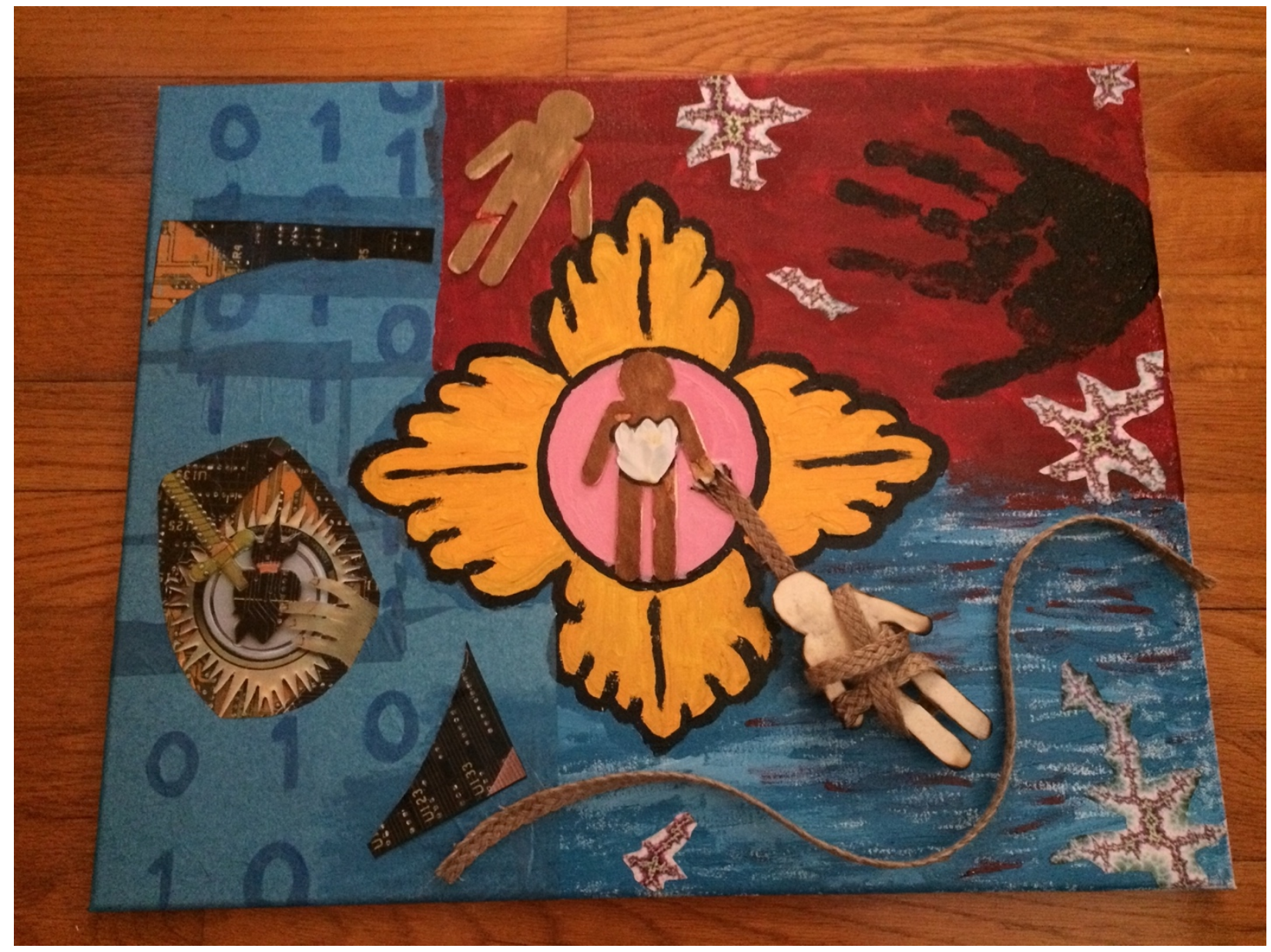


Similarly, aside from the center figure, there are two other wounded individuals in the collage. One of them is the aforementioned body that is slightly burned and tied up in rope being rescued; the rope symbolizes struggle, confinement, and feelings of being overwhelmed. The other injured brown figure has their right leg and left arm cut off, with the severed arm extending to the awaiting bodhisattva. The bodhisattva also has wounds, trying to reach out to assist others and wearing a white lotus flower that is beginning to open, representative of the initiation of enlightenment.

The left side of the collage is symbolic of the digital space that I and my Radical Dharma community reside in together. It is designated by the binary code displayed vertically, the bits of circuitry, and the blue decoupage. There is a digital version of the Virgin Mary's Immaculate Heart in the midst of the blue background. The metallic heart has a sword coming out of it and represents undying love for humanity. It also speaks to sorrow and the release of pain; the virtual fugitive space provides our community members a synchronous electronic experience of fellowship and love.

Ultimately, the pandemic has encouraged mindfulness practitioners to use technology to seek one another out and to connect our hearts, minds, and spirits through digital space. We search for individual and collective mending and sensemaking. We realize that computer-mediated interaction is a poor substitute for sharing physical space and contact. However, we are grateful for the opportunity to be together in real time, and we relish hearing the beautiful sound of everyone saying goodbye to each other asynchronously over the wireless network every time we "meet."

\section{References}

Annamma, S.A., Connor, D., \& Ferri, B. (2013) Dis/ability critical race studies (DisCrit): Theorizing at the intersections of race and dis/ability. Race Ethnicity and Education, 16(1), 1-31. https://doi.org/10.1080/13613324.2012.730511

Delgado, R. \& Stefancic, J. (2001) Critical race theory: An introduction. New York: New York University Press.

Ortiz, N. (2018) Sustaining spirit: Self-care for social justice. Berkeley, CA: Reclamation Press.

Piepzna-Samarasinha, L.L. (2018) Care work: Dreaming disability justice. Vancouver, BC: Arsenal Pulp Press.

Stovall, D. (2015) Normalizing Black death: Michael Brown, Marissa Alexander, Dred 
Scott, and the apartheid state. In K. Fasching-Varner, N.D. Hartlep (Eds.), The assault on communities of color: Exploring the realities of race-based violence (pp. 67-71). Lanham, Maryland: Rowman \& Littlefield Publishers, Inc.

williams, R.a.K., \& Owens, L.R. (2016) Radical Dharma: Talking race, love, and liberation. Berkeley, CA: North Atlantic Books.

\section{Biography}

Dr Lisette E. Torres is a scientist and disabled scholar-activist in the field of higher education. She has a doctorate in Education with a Certificate in Social Justice from Iowa State University and M.S. in Zoology with a Certificate in Ecology from Miami University. Her research focuses on racialized gender justice and disability in science and higher education. Torres is formerly the Director of the Cooper Center at Nebraska Wesleyan University. She now works for TERC, a math and science education research non-profit located in Cambridge, MA. Torres serves as a Lead and Accessibility Editor for Science for the People Magazine (Online) and a co-founder and board member of the National Coalition for Latinxs with Disabilities (CNLD).

E: lisette_torres@terc.edu 